\title{
Biological Control of Apple Ring Rot on Fruit by Bacillus amyloliquefaciens 9001
}

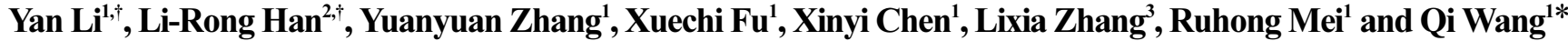 \\ ${ }^{\prime}$ Key Laboratory of Plant Pathology, Ministry of Agriculture, Department of Plant Pathology, China Agricultural University, No. \\ 2 Yuanmingyuan West Road, Haidian District, Beijing 100193, China \\ ${ }^{2}$ Research and Development Center of Biorational Pesticides, Northwest A \& F University, Yangling, Shaanxi 712100, China \\ ${ }^{3}$ China Green Health Agriculture (Beijing) Biotechnology Co., Ltd., No. 8, Donghuan Road, Beijing Badaling Economic \\ Development Zone, Yanqing County, Beijing 102101, China
}

(Received on August 17, 2012; Revised on March 26, 2013; Accepted on March 26, 2013)

\begin{abstract}
Apple ring rot disease, caused by Botryosphaeria dothidea (Moug. ex. Fr) Ces. et de Not., is one of the most important diseases on apple fruits. In this study, strain 9001 isolated from healthy apple fruits from an infested orchard was evaluated for its biocontrol activity against apple ring rot in vitro and in vivo. Strain 9001 showed obvious antagonistic activity to $B$. dothidea YL-1 when plated on potato dextrose agar. Soaking healthy apples in the bacterial suspensions of strain 9001 prior to artificial inoculation of fungal pathogen resulted in a dramatic decrease in disease incidence when compared to the control. Moreover, either field application in the growth season or postharvest treatment of apples from infected orchards with bacterial suspensions of strain 9001 resulted in significantly reduced disease incidence within the storage period for 4 months at room temperature. Based on the phylogenetic analysis of $16 \mathrm{~S}$ rRNA and the gyr $A$ gene, strain 9001 was identified as Bacillus amyloliquefaciens. These results indicated that $B$. amyloliquefaciens 9001 could be a promising agent in biocontrol of apple ring rot on fruit, which might help to minimize the yield loss of apple fruit during the long postharvest period.
\end{abstract}

Keywords : apple, Bacillus amyloliquefaciens, biological control, Botryosphaeria dothidea

Apple ring rot disease, caused by Botryosphaeria dothidea, is one of the most important diseases on the apple fruit in China (Tang et al., 2012). It is widely distributed and is endemic in most apple planting areas, especially in Northern China. The disease is characterized by slightly sunken lesions with alternating concentric tan and brown rings on infected fruits (Kang et al., 2009). In the last seventy years,

\footnotetext{
Contributed equally in this work.

*Corresponding author.

Phone) +86-10-62731460, FAX) +86-10-62810432

E-mail)wangqi@cau.edu.cn
}

a high incidence of apple fruit rot is gradually becoming a major problem in the fruit production industry, due to an increase in planting of varieties with good quality, such as 'Fuji' cultivar which is the most widespread planted cultivar in China. This cultivar, however, is very sensitive to the disease. It is difficult to control apple ring rot as the pathogen can infect the host apple fruit latently at the growth stage, and induce rot during storage. Botryosphaeria dothidea infection causes losses of up to $50 \%$ before harvest and another $79 \%$ is lost in storage on susceptible apple cultivars (Kexiang et al., 2002; Tang et al., 2012).

Currently, the most popular and effective management strategy for controlling ring rot disease in China is the application of synthetic fungicides. In concert with this technique, each fruit is bagged individually on the tree right after fruit setting to protect them from diseases. Fungicides are currently sprayed 10 or more times during each season. However, wide application of chemical fungicides inevitably leads to serious environmental problems, such as the socalled "3R-problem" (resistance, resurgence and residue). Some beneficial microbes have also been killed, thus disturbing the ecological balance and ultimately accelerating the development of the disease. Therefore, alternative strategies for controlling ring rot disease of apple are needed. Biological control with microbial antagonists has emerged as a promising alternative that can reduce synthetic fungicide usage with a low environmental impact (Sharma et al., 2009; Wisniewski and Wilson, 1992). Several genera of bacteria and fungi have been exploited and widely investigated against different fungal pathogens. The Bacillus species is one of the most studied and commercialized biological control agents (Nicholson, 2002). The multilayered cell wall structure, various modes of action, and formation of stress-resistant spores enhance the viability of Bacillus spp. in different environmental conditions as well as in different bio-formulations (Errington, 2003; Hamdache et al., 2011; Lee et al., 2012; Santoyo et al., 2012). Several commercial products originated from Bacillus spp. are available in the 
U.S. and other countries, such as RhizoPlus (B. subtilis FZB24), Yield Shield (B. pumilus GB34), Kodiak (B. subtilis strain GB03), and Serenade (B. subtilis QST716) (Fravel, 2005; Berg, 2009). Yield Increasing Bacteria (YIB), comprised of Bacillus spp., was developed by our lab and has been wildly used to control diseases on crops, vegetables and fruit trees in China for the past 40 years. However, only limited attempts have been made to control apple ring rot disease using Bacillus.

Strain 9001 was isolated from healthy apple fruits from an infested orchard and showed significant antagonistic activity to several fungal pathogens in vitro, such as Alternaria alternate f. sp. mali, Monilinia fructiena, Rhizoctonia cerealis (unpublished data). However, its effect on apple ring rot disease is uncertain. The objective of the present study was to evaluate the biological control activity in vitro and in vivo and to phylogenetically identify it based on $16 \mathrm{~S}$ rRNA and gyrA gene sequence analysis. The results of our study may provide an alternative to the present methods of prevention to control the apple ring rot during the storage period.

\section{Materials and Methods}

Bacterial/fungal strains and growth conditions. A virulent strain B. dothidea YL1, provided by Dr. Liyun Guo (China Agricultural University), was used in an antagonistic test in vivo and in vitro. $B$. dothidea YL1 was cultured on potato dextrose agar (PDA) at $25^{\circ} \mathrm{C}$ in the dark, followed by growing on $2 \%$ malt extract agar (MEA) with $12 \mathrm{~h}$ photoperiod of near-UV light to induce sporulation (Tang et al., 2012). Mature pycnidia were collected from MEA and crushed in sterile distilled water in a micro-centrifuge tube. The conidial suspension was then filtered through three layers of lens paper to remove mycelia and pycnidial debris. The conidial concentration was determined with a hemacytometer.

Strain 9001 was cultured on nutrient agar at $30^{\circ} \mathrm{C}$ for $1-$ 2 day(s) and transferred to nutrient broth on a rotary shaker at $160 \mathrm{rpm}$ at $30^{\circ} \mathrm{C}$ for 2 days. The bacterial cells were collected by centrifugation at $6000 \times g$ for $5 \mathrm{~min}$ and adjusted to desired concentratin with sterilized distilled water. The cell concentration was determined with a hemacytmeter.

In vitro antagonism test. The in vitro antagonism effect of strain 9001 on mycelial growth of $B$. dothidea YL1 was carried out with the dual culture assay method on PDA plate. Briefly, 5-day-old mycelia disks (5 $\mathrm{mm}$ diameter) of the pathogen were placed in the center of PDA plates (90 $\mathrm{mm}$ ). Four drops of bacterial suspension were equidistantly spotted around the fungal inoculums at a distance of $3 \mathrm{~cm}$ after $24 \mathrm{~h}$ of pathogen inoculation. PDA inoculated with the pathogen alone was used as the control. Plates were incu- bated at $30^{\circ} \mathrm{C}$ for 4 days, and the antagonistic effect was assessed by measuring the inhibition zones ( $\mathrm{mm}$ ) and the colony diameters. Percentage growth inhibition was calculated using the formula $y=(a-b) / a \times 100$, where $y$ is the percentage growth inhibition; $a$ is the colony area of uninhibited $B$. dothidea YL1, and $b$ is the colony area of treated $B$. dothidea YL1 (Mikani et al., 2008). The experiments were repeated twice and results recorded as the mean of three replicates.

In vivo biological control experiment. Apples (Malus domestica, Fuji) were procured from a commercial market. The fruits were selected free of wounds and homogeneous as much as possible in physiological maturity stage and size. Selected fruits were washed with sterile water and dried in a transfer hood. The bacterial inoculum was prepared and adjusted to the concentration of $10^{5}, 10^{6}, 10^{7}$ and $10^{8} \mathrm{cfu} /$ $\mathrm{mL}$ with water, respectively. Apple fruits were soaked in the prepared bacterial suspensions for $1 \mathrm{~h}$ and then taken out and placed in plastic trays at $30^{\circ} \mathrm{C}$. After $24 \mathrm{~h}$, the bacterial-treated apples were divided into two groups. The first group, soaked by bacterial suspension at the concentrartion of $10^{8} \mathrm{cfu} / \mathrm{mL}$, was inoculated with 5-day-old mycelia disk ( $5 \mathrm{~mm}$ diameter) of the pathogen (10 pieces per apple). The second group, soaked in bacterial suspension at the concentrartion of $10^{5}, 10^{6}$, and $10^{7} \mathrm{cfu} / \mathrm{mL}$, was inoculated with $10 \mu \mathrm{l}$ of $B$. dothidea YL1 spores $\left(10^{5}\right.$ spores $/ \mathrm{mL}$ ) which were added to a circular, sterilized filter paper (5-mm-diameter, 10 pieces per apple). Apples soaked in sterile distilled water prior to exposure to the fungal pathogen were used as the control. Later, the treated apples were placed in plastic trays at $30^{\circ} \mathrm{C}$. The inside of the trays were sprayed with sterile distilled water to maintain high relative humidity. The number of infected spots were recorded and the disease incidence (DI) was calculated using the following formula: DI $(\%)=$ the number of the infected spots/total number of the spots inoculated $\times 100$. The experiments were repeated twice and results recorded as the mean of three replicates.

Biological control trials in the storage period. Two sets of apples were used to evaluate the biocontrol activity of stain 9001 on apple ring rot in the storage period. One set of apples was sampling from an orchard, containing 10-yearold apple trees (Fuji) severely infected by $B$. dothidea, and situated at Beiliu village, Changping District, Beijing, China. In the orchard, eight trees were chosen for the biocontrol trial. Bacterial suspensions of strain 9001 at the concentration of $10^{8} \mathrm{cfu} / \mathrm{mL}$ were sprayed on four trees on May 11, June 5, June 30 and Sept. 20 during the growing season. The other four trees sprayed with tap water were used as the control. Routine chemical control was applied around the 
experimental field. After fruit maturation, 50 apples from each tree were harvested and stored at room temperature. The number of rot fruits was recorded at 15-day intervals and the disease incidence was calculated.

The second treatment group of apples was sampled from the same orchard, but at a different site from our original experimental site, where only routine chemical control was applied. After fruit maturation, the apples were harvested and soaked in bacterial suspensions of strain 9001 at the concentration of $10^{8} \mathrm{cfu} / \mathrm{mL}$ for $1-2 \mathrm{~min}$ and dried in a transfer hood. Apples soaked in sterile distilled water were used as the control. The treated apples were placed in plastic trays at room temperature. The number of rot fruits was recorded at 15 day intervals and the disease incidence was calculated. Ten fruits were used for each replicate and results recorded as the mean of four replicates for each treatment.

Phylogenetic identification of strain 9001 based on $16 \mathrm{~S}$ rRNA and gyrA gene sequence analysis. The 16S rRNA gene was amplified with the primers 63F (5'-CAGGCCT AACACATGCAAGTC-3') and 1387R (5'-GGGCGGWGT GTACAAGGC-3'), which is specific for bacteria 16S rDNA (Marchesi et al., 1998). A part of the gyrA gene was amplified with the primers p-gyrA-f (5'-CAGTCAGGAAATGC GTACGTCCTT-3') and p-gyrA-r (5'-CAAGGTAATGCTC CAGGCATTG CT-3') (Chun and Bae, 2000). The PCR amplification was performed by using a Taq DNA polymerase kit (Beijing TransGen Biotech Co., Ltd) with a modified thermocycler protocol which included an initial denaturation at $95^{\circ} \mathrm{C}$ for $5 \mathrm{~min}$ followed by 35 cycles of denaturation at $95^{\circ} \mathrm{C}$ for $1 \mathrm{~min}$, annealing at $56^{\circ} \mathrm{C}$ for $40 \mathrm{~s}$, and extension at $72^{\circ} \mathrm{C}$ for $1 \mathrm{~min}$; and a final extension at $72^{\circ} \mathrm{C}$ for $10 \mathrm{~min}$ ( $\mathrm{Li}$ et al., 2012). PCR products were ligated into the pMD19-T vector (Takara Co. Ltd.) and the recombinant plasmid was harvested from an overnight $\mathrm{LB}$ culture using the StarPrep Plasmid Miniprep Kit (GenStar Biosolutions Co. Ltd) and sent to Sanboyuanzhi Biotechnologies Co. Ltd. for sequencing. The phylogenetic tree of strain 9001 based on gyrA gene was constructed using the neighbor-joining method of Mega 4.0 software (Tamura et al., 2007). A bootstrap analysis of 1,000 replications was carried out. The sequence of B. cereus ATCC14579 was used as the outgroup for rooting the phylogenetic trees.

\section{Results}

In vitro antagonism test. To investigate the antagonistic activity of strain 9001 to $B$. dothidea YL1, the dual culture assay was conducted. Four days after inoculation, inhibitory halos were observed in the dual culture dishes (Fig. 1). The inhibition zone was $3.5-4.7 \mathrm{~mm}$ and the average percent-

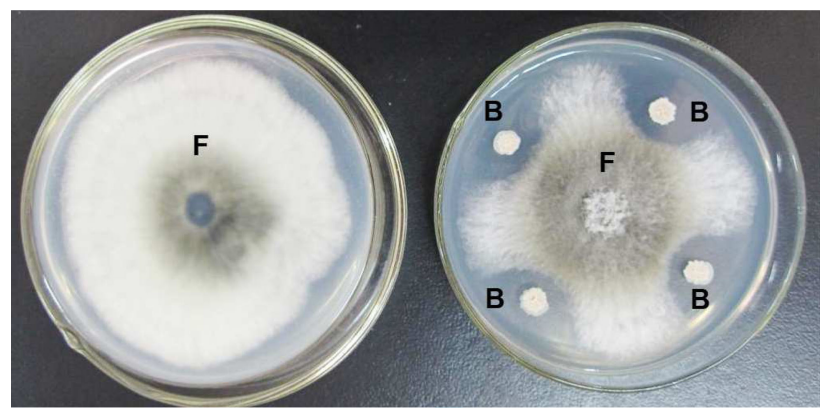

Fig. 1. Bacterial strain 9001 (B) showing significant antagonistic activity in dual culture study against fungal pathogen Bacillus dothidea YL1 (F) on PDA.

age growth inhibition was $42.57 \%$, suggesting that strain 9001 could significantly inhibit the growth rate of fungal pathogen $B$. dothidea YL1.

In vivo biological control experiment. To investigate the potential biological control activity of strain 9001 against $B$. dothidea YL1 in vivo, apples were treated with a bacterial suspension prior to fungal exposure. The symptoms started to appear 12 days post inoculation when apples were soaked in a bacterial suspension at a concentration of $10^{8}$ $\mathrm{cfu} / \mathrm{mL}$ prior to exposure to the mycelium plugs (Table 1). Symptoms appeared 7 days post inoculation for untreated apples (data not shown). The disease index of untreated apples was about 38 and 10 times higher than that of the bacterial-suspension treated apples 12 and 14 days post inoculation, respectively (Table 1).

In the field, re-infection of apple ring rot disease was mainly caused by the fungal spores. Therefore, after being immersed in different concentrations of Bacillus strain 9001, apples were inoculated with fungal spores at the concentration of $10^{5}$ spores $/ \mathrm{mL}$. The data showed that apples treated with strain 9001 at the concentration of either $10^{6}$ or $10^{7} \mathrm{cfu} / \mathrm{mL}$ showed no symptoms until 37 days after inoculation (Table 2). In contrast, apples treated with sterile

Table 1. The disease incidence of spots inoculated with mycelial disks of the pathogen

\begin{tabular}{ccccc}
\hline \hline \multirow{2}{*}{ Treatment } & \multicolumn{4}{c}{$\operatorname{Avg} \mathrm{DI} \pm \mathrm{SD}^{\mathrm{a}}$ at: } \\
\cline { 2 - 5 } & 8 day & 10 day & 12 day & 14 day \\
\hline $9001-10^{8}$ & $0.0 \pm 0.0$ & $0.0 \pm 0.0^{*}$ & $2.2 \pm 3.8^{*}$ & $11.1 \pm 10.2^{*}$ \\
Control & $24.4 \pm 19.2$ & $57.8 \pm 30.1$ & $84.4 \pm 26.9$ & $100.0 \pm 0.0$ \\
\hline
\end{tabular}

${ }^{a}$ The disease incidence (DI) was determined 8 - 14 days after inoculation of the pathogen after being soaked in the bacterial suspensions of strain 9001 at the concentration of $10^{8} \mathrm{cfu} / \mathrm{mL}\left(9001-10^{8}\right)$ or water (control). Values are representative of two experiments, and three replicates were used for each experiment. Asterisks indicate statistically significant differences in DI between the control and treatment with bacterial suspensions of strain $9001(P<0.05$, Student's $t$ test $)$. 
Table 2. The disease incidence of spots inoculated with fungal spores of the pathogen

\begin{tabular}{ccccccc}
\hline \hline \multirow{2}{*}{ Treatment } & \multicolumn{5}{c}{ Avg DI $\pm \mathrm{SD}^{\mathrm{a}}$ at: } \\
\cline { 2 - 6 } & 20 day & 24 day & 27 day & 33 day & 37 day & 39 day \\
\hline $9001-10^{5}$ & $0.0 \pm 0.0^{*}$ & $10.0 \pm 0.0^{*}$ & $20.0 \pm 0.0^{*}$ & $33.3 \pm 5.8$ & $50.0 \pm 10.0$ & $50.0 \pm 10.0$ \\
$9001-10^{6}$ & $0.0 \pm 0.0^{*}$ & $0.0 \pm 0.0^{*}$ & $0.0 \pm 0.0^{*}$ & $0.0 \pm 0.0^{*}$ & $0.0 \pm 0.0^{*}$ & $3.3 \pm 5.8^{*}$ \\
$9001-10^{7}$ & $0.0 \pm 0.0^{*}$ & $0.0 \pm 0.0^{*}$ & $0.0 \pm 0.0^{*}$ & $0.0 \pm 0.0^{*}$ & $0.0 \pm 0.0^{*}$ & $0.0 \pm 0.0^{*}$ \\
Control & $20.0 \pm 0.0$ & $26.7 \pm 5.8$ & $33.3 \pm 5.8$ & $40.0 \pm 0.0$ & $46.7 \pm 5.8$ & $56.7 \pm 5.8$ \\
\hline
\end{tabular}

${ }^{\mathrm{a}}$ The DI was determined $12-39$ days post inoculation of the pathogen after being soaked in the water (control) or the bacterial suspensions of strain 9001 at the concentration of $10^{5}\left(9001-10^{5}\right), 10^{6}\left(9001-10^{6}\right)$ or $10^{7}\left(9001-10^{7}\right) \mathrm{cfu} / \mathrm{mL}$. Values are representative of two experiments, and three replicates were used for each experiment. Asterisks indicate statistically significant differences in DI between the control and treatment with bacterial suspensions of strain $9001(P<0.05$, Student's $t$ test $)$.

distilled water showed rot symptoms 20 days post inoculation (Table 2). Apples treated with strain 9001 at the concentration of either $10^{5} \mathrm{cfu} / \mathrm{mL}$ showed rot symptoms 24 days after inoculation. However, its disease incidence was significantly lower than that of control until 27 days post inoculation (Table 2). These results suggested that strain 9001 has potential biocontrol activity of against $B$. dothidea YL1 in vivo and its activity was positively correlated to the concentration used.

Biological control trials in the postharvest period. During the growth season, a group of apple trees were sprayed
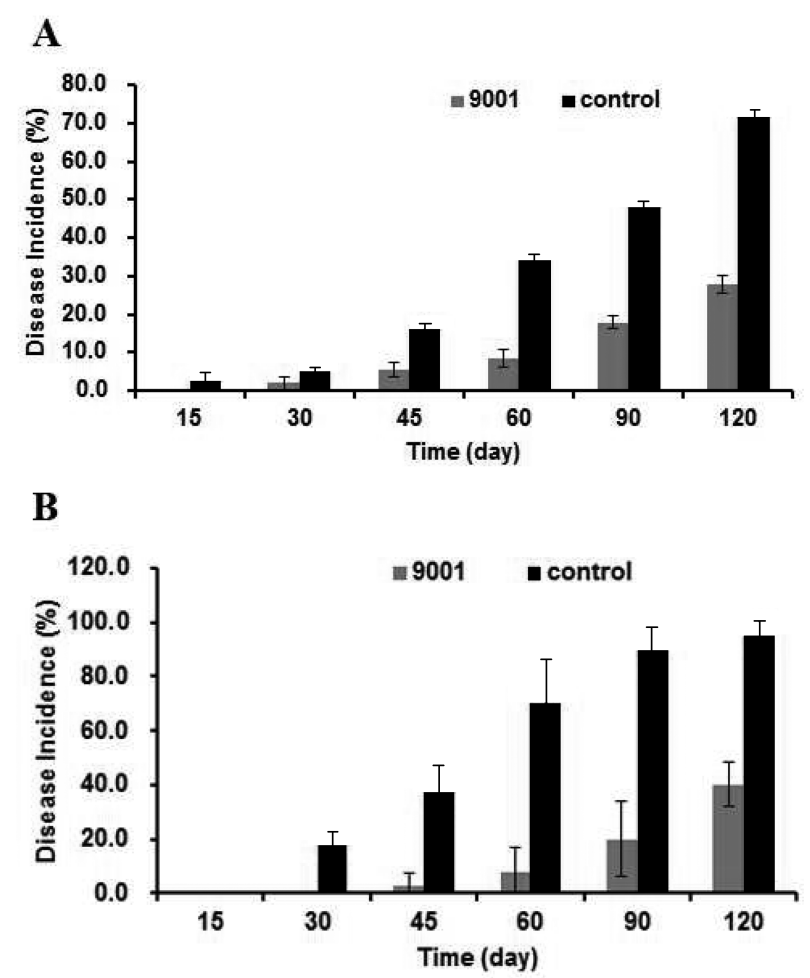

Fig. 2. The disease incidence of apple ring rot on apples treated with bacterial suspensions of strain 9001 (9001) and water (control) in the postharvest period. (A) the apples were treated in the growth season; (B) the apples were treated after harvest. with the Bacillus strain 9001 suspension. During this treatment, the disease incidence was $0.25-0.40$-fold of that of the group treated with sterile distilled water at all the time points investigated in the storage period at room temperature (Fig. 2A). Similar results were obtained when the apples, untreated in the growth season, were only treated with bacterial suspension of strain 9001 after harvest (Fig. 2B). This result suggested that no matter when the apples were treated with the bacteria, either during the growth season or after harvest, bacterial strain 9001 was effective in controlling apple ring rot in the long postharvest period.

Phylogenetic identification of strain 9001 based on 16S rRNA and gyrA gene sequence analysis. Based on $16 \mathrm{~S}$ rRNA gene sequence analysis, an NCBI BLAST search yielded a close similarity to $B$. amyloliquefaciens strain DM09 and B. subtilis strain M16K 16S rRNA, indicating that strain 9001 belongs to the species B. amyloliquefaciens or B. subtilis. This was clarified by the sequence of the

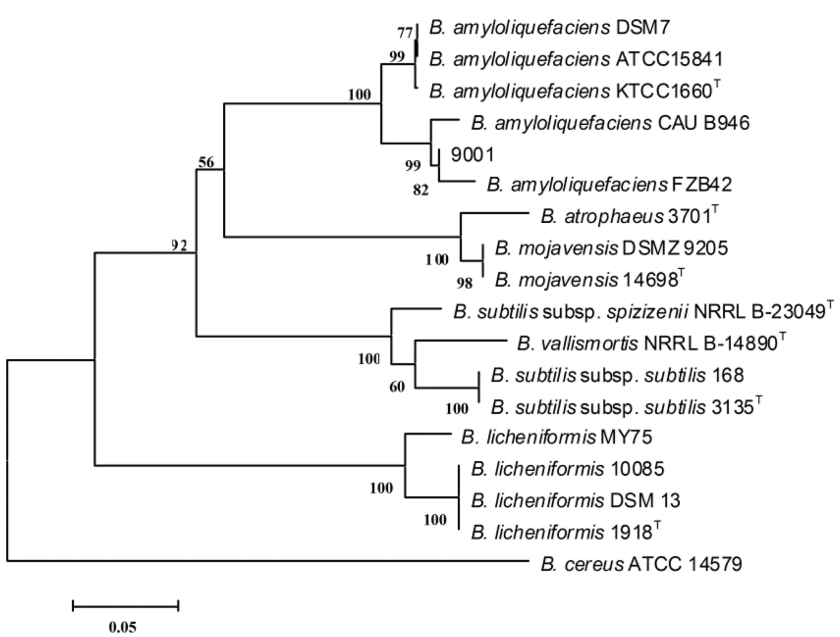

Fig. 3. Rooted neighbor-joining tree based on partial gyr $A$ nucleotide sequences. The percentage numbers at the nodes indicate the levels of bootstrap support based on neighbor-joining analyses of 1000 resampled data sets. The scale bar indicates 0.05 nucleotide substitutions per nucleotide position. Letter T marks type strains. 
gyrase gene gyr $A$, which has previously been shown to be effective for resolving these closely related taxa of the $B$. subtilis group (Chun and Bae, 2000). Partial sequence of gyr $A$ was amplified, aligned, and a neighbor-joining tree was built. Strain 9001 was recovered close to B. amyloliquefaciens strain FZB42 and CAU946, and clustered in the same group with other $B$. amyloliquefaciens strains, including the type strain B. amyloliquefaciens KTCC1660 (Fig. 3). Therefore, strain 9001 was identified as B. amyloliquefaciens.

\section{Discussion}

Biological control using microorganisms associated with plants is an efficient and effective approach to control diseases and is considered environmentally-friendly. The first step is to screen potential biological control agents (BCA), and the main screening strategy used by many scientists is based on antagonistic activity in vitro. Spores are the major inoculants both in the field and in the postharvest period for many plant diseases, such as apple ring rot disease. Hence, an assay involving spores of pathogens and isolates were expected to give more realistic picture than dual culture assay. In our results, the supernatant of $B$. amyloliquefaciens 9001 cell culture showed a strong inhibition of spore germination of the pathogen $B$. dothidea YL1 in vitro (Table 2). This result is consistent with previous studies reporting that $B$. subtilis has effectively inhibited the spore germination of several pathogens (Li et al., 2009; Lee et al., 2012; Zhang et al., 2009).

Multiple modes of action of Bacillus spp. were assumed to contribute to their successful biocontrol, such as nutrient and space competition, induced resistance and production of diffusible antibiotics, volatile organic compounds, toxins, biosurfactants, and extracellular cell wall-degrading enzymes such as chitinases and $\beta$-1,3-glucanase (Berg, 2009; Droby et al., 2009; Nunes, 2012). Numerous studies have reported a range of antifungal compounds produced by Bacillus spp. and the importance of the antifungal compounds in biocontrol activity (Arras and Arru, 1997; Cao et al., 2012; Kong et al., 2012; Lee et al., 2009; Liu et al., 2011; Ongena and Jacques, 2008; Santoyo et al., 2012; Vitullo et al., 2012; Yanez-Mendizabal et al., 2012; Ye et al., 2012; Yu et al., 2002). Among them, lipopeptides from the fengycin, iturin, and surfactin families was thought to be key factors for the biological control activity (Ongena and Jacques, 2008; Santoyo et al., 2012; Stein, 2005). B. amyloliquefaciens 9001 strongly inhibited the growth of the pathogen in dual culture, probably due to its production of iturin, sufactin and fengycins. To further validate the biosynthsis of lipopeptides and their function in biological control, isolation and purification of the antifungal compounds from the cell- free supernatant of B. amyloliquefaciens 9001 and matrixassisted laser desorption ionization-time of flight analysis will be done in the future. Lytic enzymes produced by Bacillus spp. is also considered to play a key factor in the biological control activity (Janisiewicz and Korsten, 2002). Further research is required to explore this mechanism of biocontrol.

A successful biocontrol agent is generally equipped with several mechanisms which often work in concert, and may be crucial for controlling disease development. It involves a complex interaction between host, pathogen, antagonists and environment (Droby et al., 2009; Nunes, 2012). In this study, field application of B. amyloliquefaciens 9001 in the growth season resulted in dramatic reduction of disease incidence on fruit during the storage period (Fig. 2A). It is in agreement with a previous report that pre-harvest application of Epicoccum nigrum was effective for controlling postharvest brown rot in peaches (Larena et al., 2005). It is probably because pre-harvest application of the BCA allowed the antagonist to have longer interaction with the pathogen and to colonize tissues before the arrival of the pathogen and enhanced the biocontrol system.

In conclusion, B. amyloliquefaciens 9001 was found to have effective biocontrol activity against apple ring rot in vitro and in vivo. Moreover, either field application in the growth season or postharvest treatment of apples from infected orchard with bacterial suspensions of B. amyloliquefaciens 9001 resulted in significantly reduced disease incidence in the storage period. These results indicated that B. amyloliquefaciens 9001 could be a promising agent in biocontrol of apple ring rot on fruit. Further research is required to explore its mechanism of biocontrol.

\section{Acknowlegments}

This work was financially supported by grants from Beijing Natural Science Foundation (Grant number: 6101001) and the Earmarked Fund for Modern Agro-industry Technology Research System (Grant number: CARS-28).

\section{References}

Arras, G. and Arru, S. 1997. Mechanism of action of some microbial antagonists against fungal pathogens. Ann. Microbiol. Enzimol. 47:97-120.

Berg, G. 2009. Plant-microbe interactions promoting plant growth and health: perspectives for controlled use of microorganisms in agriculture. Appl. Microbiol. Biotechnol. 84:11-18.

Cao, Y., Xu, Z.H., Ling, N., Yuan, Y. J., Yang, X. M., Chen, L. H., Shen, B. and Shen, Q. R. 2012. Isolation and identification of lipopeptides produced by B. subtilis SQR 9 for suppressing Fusarium wilt of cucumber. Sci. Hortic. (Amsterdam) 135:3239. 
Chun, J. and Bae, K. S. 2000. Phylogenetic analysis of Bacillus subtilis and related taxa based on partial gyrA gene sequences. Anton. Leeuw. Int. J. G. 78:123-127.

Droby, S., Wisniewski, M., Macarisin, D. and Wilson, C. 2009. Twenty years of postharvest biocontrol research: Is it time for a new paradigm? Postharvest Biol. Tech. 52:137-145.

Errington, J. 2003. Regulation of endospore formation in Bacillus subtilis. Nat. Rev. Microbiol. 1:117-126.

Fravel, D. R. 2005. Commercialization and implementation of biocontrol. Annu. Rev. Phytopathol. 43:337-359.

Hamdache, A., Lamarti, A., Aleu, J. and Collado, I. G. 2011. Nonpeptide metabolites from the genus Bacillus. J. Nat. Prod. 74:893-899.

Janisiewicz, W. J. and Korsten, L. 2002. Biological control of postharvest diseases of fruits. Annu. Rev. Phytopathol. 40: 411-441.

Kang, L., Hao, H., Zhenying, Y., Li, X. and Kang, G. 2009. The advances in the research of apple ring rot. Chin. Agric. Sci. Bull. 25:188-191.

Kexiang, G., Xiaoguang, L., Yonghong, L., Tianbo, Z. and Shuliang, W. 2002. Potential of Trichoderma harzianum and T. atroviride to control Botryosphaeria berengeriana f. sp. piricola, the cause of apple ring rot. J. Phytopathol. 150:271-276.

Kong, H. G., Kim, J. C., Choi, G. J., Lee, K. Y., Kim, H. J., Hwang, E. C., Moon, B. J. and Lee, S. W. 2012. Production of furfactin and iturin by Bacillus lichenifortnis N1 responsible for plant disease control activity. Plant Pathol. J. 26:170-177.

Larena, I., Torres, R., De Cal, A., Linan, M., Melgarejo, P., Domenichini, P., Bellini, A., Mandrin, J. F., Lichou, J., de Eribe, X. O. and Usall, J. 2005. Biological control of postharvest brown rot (Monilinia spp.) of peaches by field applications of Epicoccum nigrum. Biol. Conc. 32:305-310.

Lee, G. W., Ko, J. A., Oh, B. T., Choi, J. R., Lee, K. J., Chae, J. C. and Kamala-Kannan, S. 2012. Biological control of postharvest diseases of apples, peaches and nectarines by Bacillus subtilis S16 isolated from halophytes rhizosphere. Biocontrol Sci. Technol. 22:351-361.

Lee, K. Y., Heo, K. R., Choi, K. H., Kong, H. G., Nam, J., Yi, Y. B., Park, S. H., Lee, S. W. and Moon, B. J. 2009. Characterization of a chitinase gene exhibiting antifungal activity from a biocontrol bacterium Bacillus licheniformis N1. Plant Pathol. J. 25:344-351.

Li, J., Yang, Q., Zhao, L. H., Zhang, S. M., Wang, Y. X. and Zhao, X. Y. 2009. Purification and characterization of a novel antifungal protein from Bacillus subtilis strain B29. J. Zhejiang Univ. Sci. B 10:264-272.

Li, L. H., Ma, J. C., Li, Y., Wang, Z. Y., Gao, T. T. and Wang, Q. 2012. Screening and partial characterization of Bacillus with potential applications in biocontrol of cucumber Fusarium wilt. Crop Prot. 35:29-35.

Liu, J., Zhou, T., He, D., Li, X. Z., Wu, H. J., Liu, W. Z. and Gao, X. W. 2011. Functions of lipopeptides bacillomycin D and fengycin in antagonism of Bacillus amyloliquefaciens C06 towards Monilinia fructicola. J. Mol. Microbiol. Biotechnol. 20:43-52.

Marchesi, J. R., Sato, T., Weightman, A. J., Martin, T. A., Fry, J.
C., Hiom, S. J. and Wade, W. G. 1998. Design and evaluation of useful bacterium-specific PCR primers that amplify genes coding for bacterial 16S rRNA. Appl. Environ. Microbiol. 64:795-799.

Mikani, A., Etebarian, H. R., Sholberg, P. L., O'Gorman, D. T., Stokes, S. and Alizadeh, A. 2008. Biological control of apple gray mold caused by Botrytis mali with Pseudomonas fluorescens strains. Postharvest Biol. Tech. 48:107-112.

Nicholson, W. L. 2002. Roles of Bacillus endospores in the environment. Cell. Mol. Life Sci. 59:410-416.

Nunes, C. 2012. Biological control of postharvest diseases of fruit. Eur. J. Plant Pathol. 133:181-196.

Ongena, M. and Jacques, P. 2008. Bacillus lipopeptides: versatile weapons for plant disease biocontrol. Trends Microbiol. 16: $115-125$.

Santoyo, G., Orozco-Mosqueda, M. D. and Govindappa, M. 2012. Mechanisms of biocontrol and plant growth-promoting activity in soil bacterial species of Bacillus and Pseudomonas: a review. Biocontrol Sci. Technol. 22:855-872.

Sharma, R. R., Singh, D. and Singh, R. 2009. Biological control of postharvest diseases of fruits and vegetables by microbial antagonists: A review. Biol. Conc. 50:205-221.

Stein, T. 2005. Bacillus subtilis antibiotics: structures, syntheses and specific functions. Mol. Microbiol. 56:845-857.

Tamura, K., Dudley, J., Nei, M. and Kumar, S. 2007. MEGA4: Molecular evolutionary genetics analysis (MEGA) software version 4.0. Mol. Biol. Evol. 24:1596-1599.

Tang, W., Ding, Z., Zhou, Z., Wang, Y. and Guo, L. 2012. Phylogenetic and pathogenic analyses show that the causal agent of apple ring rot in China is Botryosphaeria dothidea. Plant Dis. 96:486-496.

Vitullo, D., Di Pietro, A., Romano, A., Lanzotti, V. and Lima, G. 2012. Role of new bacterial surfactins in the antifungal interaction between Bacillus amyloliquefaciens and Fusarium oxysporum. Plant Pathol. 61:689-699.

Wisniewski, M. E. and Wilson, C. L. 1992. Biological control of postharvest diseases of fruits and vegetables: recent advances. HortScience 27:94-98.

Yanez-Mendizabal, V., Zeriouh, H., Vinas, I., Torres, R., Usall, J., de Vicente, A., Perez-Garcia, A. and Teixido, N. 2012. Biological control of peach brown rot (Monilinia spp.) by Bacillus subtilis CPA-8 is based on production of fengycin-like lipopeptides. Eur. J. Plant Pathol. 132:609-619.

Ye, Y. F., Li, Q. Q., Fu, G., Yuan, G. Q., Miao, J. H. and Lin, W. 2012. Identification of antifungal substance (Iturin $\mathrm{A}_{2}$ ) produced by Bacillus subtilis B47 and its effect on southern corn leaf blight. J. Integr. Agric. 11:90-99.

Yu, G. Y., Sinclair, J. B., Hartman, G. L. and Bertagnolli, B. L., 2002. Production of iturin A by Bacillus amyloliquefaciens suppressing Rhizoctonia solani. Soil Biol. Biochem. 34:955963.

Zhang, J. X., Xue, A. G. and Tambong, J. T. 2009. Evaluation of seed and soil treatments with novel Bacillus subtilis strains for control of soybean root rot caused by Fusarium oxysporum and F. graminearum. Plant Dis. 93:1317-1323. 